\title{
Response to comment on Brunnekreef et al.: Is etoricoxib effective in preventing heterotopic ossification after primary total hip arthroplasty?
}

\author{
Jaap J. Brunnekreef • Berend W. Schreurs
}

Published online: 19 June 2013

(C) Springer-Verlag Berlin Heidelberg 2013

We thank the authors for their constructive comments and would like to answer their questions.

1. We do not believe that differences in operative skills would have influenced our outcome. All 42 patients were operated upon by two senior orthopaedic staff members. One operated on 25 hips with his team and the other operated on 17 hips. Both orthopaedic surgeons have extensive orthopaedic skills and have been working together for many years in hip surgery. We believe their operative skills are comparable. We are not aware of studies that have reported the influence of surgical skills on the heterotopic ossification rate after total hip prostheses.

2. From previous studies on this topic we have not seen heterotopic ossifications that occurred in the interval between six and 12 months. There may, in rare cases, be some progression of the extension of the heterotopic ossification after six months, however this is very unlikely. Therefore, we think six months follow-up is sufficient.

3. The radiological assessment was done by one independent radiologist. The radiologist is an highly qualified radiologist, who is specialised in the assessment of orthopaedic images. Possibly it would have been better to use two radiologists, we will take your recommendation for future studies.

4. We totally agree with your comment. In our hospital we have standardised AP pelvic photographs.

5. We agree with the author that future large scale patient and control research is needed to further study the positive effect of a COX-2 inhibitor in the prevention of heterotopic ossifications. Indeed, a previous study on the effect of rofecoxib investigated using both a small pilot study [1] and a large randomised controlled trial [2]. The dose and time administration of COX-2 inhibitors is an interesting research suggestion.

\section{References}

1. van der Heide HJ, Koorevaar RC, Lemmens JA, van Kampen A, Schreurs BW (2007) Rofecoxib inhibits heterotopic ossification after total hip arthroplasty. Arch Orthop Trauma Surg 127(7):557561

2. van der Heide HJ, Rijnberg WJ, Van Sorge A, Van Kampen A, Schreurs BW (2007) Similar effects of rofecoxib and indomethacin on the incidence of heterotopic ossification after hip arthroplasty. Acta Orthop 78(1):90-94
J. J. Brunnekreef • B. W. Schreurs ( $\square)$

Department of Orthopaedics, Radboud University Nijmegen

Medical Centre, Geert Grooteplein 10,

6500 HB, Nijmegen, The Netherlands

e-mail: B.Schreurs@orthop.umcn.nl 